\title{
Crystal Structure of a Bioactive Intermediate: 1-Benzhydrylpiperazine
}

\author{
S. Naveen, ${ }^{*}$ S. Nanjunda Swamy, ** Basappa, ${ }^{* *}$ B. Prabhu Swamy, ** Sridhar M. Anandalwar, ${ }^{* \dagger}$ \\ Javaregowda S. PRASAD, $*$ and Kanchugarakoppal S. RANGAPPA**
}

*Department of Studies in Physics, University of Mysore, Mysore 570 006, India

**Department of Studies in Chemistry, University of Mysore, Mysore 570 006, India

\begin{abstract}
A new bioactive intermediate, 1-benzhydrylpiperazine, crystallizes in monoclinic space group $P 2_{1} / c$ with cell parameters $a=10.171(8) \AA, b=9.599(5) \AA, c=15.526(13) \AA, \beta=107.861(2)^{\circ}$ and $Z=4$. The piperazine ring is in the chair conformation.
\end{abstract}

(Received August 29, 2005; Accepted November 30, 2005; Published on web March 13, 2006)

1-Benzhydrylpiperazine bearing dihydronaphthalene derivatives are found to possess excellent pharmacological activities, such as vasodilator, hypotensive and cerebral blood flow increasing actions. ${ }^{1}$ Recently, a series of pyrazolo[3,4-d]pyrimidines were synthesized using 1-benzhydrylpiperazine, and their antiviral activity was evaluated. It was found that they are very specific for human enteroviruses, particularly coxsackieviruses at nanomolar concentrations. ${ }^{2}$ We report here the single-crystal $\mathrm{x}$ ray structure of the title compound, which is an intermediate for the synthesis of the antipsychotic drug. A schematic diagram of the molecule is shown in Fig. 1.

A single crystal of the title compound with dimensions of 0.25 $\times 0.3 \times 0.25 \mathrm{~mm}$ was chosen for an X-ray diffraction study. Measurements were made on a DIPLabo Imaging Plate system with graphite monochromated Mo $K_{\alpha}$ radiation. Thirty six frames of data were collected by the oscillation method, with each frame being exposed for $300 \mathrm{~s}$. Successive frames were scanned in steps of $5^{\circ} \mathrm{min}$ with an oscillation range of $5^{\circ}$. Image processing and data reduction were performed using Denzo. ${ }^{3}$ All the frames could be indexed using a primitive monoclinic lattice. The reflections were merged with Scalepack. ${ }^{4}$ The structure was solved by direct methods using SHELXS97. ${ }^{5}$ All of the non-hydrogen atoms were revealed in the first map, itself. Anisotropic refinement using SHELXL975 was started at this stage and the residual $R_{1}$ finally converged to 0.0621 .

The hydrogen atoms were placed at chemically acceptable positions and were not refined. Details of the crystal and refinement data are given in Table 1. Table 2 gives the selected bond lengths and bond angles of the non-hydrogen atoms. The

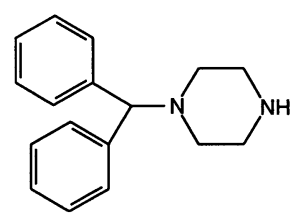

Fig. 1 Schematic diagram.

$\dagger$ To whom correspondence should be addressed.

E-mail: mas@physics.uni-mysore.ac.in bond lengths and bond angles are in good agreement with the standard values. An ORTEP diagram of the molecule with thermal ellipsoids at 50\% probability is shown in Fig. 2.

A study of the torsion angles, asymmetric parameters and least-squares plane calculations reveals that the piperazine ring in the structure is in the chair conformation. The dihedral angles between the piperazine ring and the benzene rings $(\mathrm{C} 15-\mathrm{C} 19)$ and (C8-C13) are $86.32(10)^{\circ}$ and $88.27(15)^{\circ}$, respectively, indicating that the benzene rings are nearly perpendicular to the piperazine ring. The dihedral angle between the two benzene rings is $81.12(11)^{\circ}$, which is very low when compared to 1-[(4-chlorophenyl)phenylmethyl] piperazine. ${ }^{6}$ The piperazine ring is in a chair conformation. This has been confirmed by the puckering parameters $q_{2}=$ $0.008(2) \AA, q_{3}=0.591(2) \AA, Q_{\mathrm{T}}=0.592(2)$ and $\theta=0.53(2)^{\circ}$. A ring puckering analysis ${ }^{7}$ shows that the piperazine ring has a

Table 1 Crystal and experimental data

\begin{tabular}{ll} 
CCDC 286657 & \\
Empirical formula & $\mathrm{C}_{17} \mathrm{H}_{20} \mathrm{~N}_{2}$ \\
Formula weight & 252.35 \\
Crystal system & monoclinic \\
Space group & $P 2_{1} / c \quad Z=4$ \\
Cell dimensions & $a=10.171(8) \AA$ \\
& $b=9.599(5) \AA$ \\
& $c=15.526(13) \AA$ \\
& $\beta=107.861(2)^{\circ}$ \\
Volume & $1442.8(2) \AA^{3}$ \\
$D_{c}$ & $1.162 \mathrm{Mg} / \mathrm{m}^{3}$ \\
$\theta_{\max }$ & $32.51^{\circ}$ \\
Independent reflections & $4912[R(\mathrm{int})=0.0232]$ \\
Refinement method & Full-matrix least-squares on $F^{2}$ \\
Data/restraints/parameters & $4912 / 0 / 173$ \\
Final $R$ indices $[I>2 \sigma(I)]$ & $R 1=0.0621[2822$ reflns $]$ \\
& $w R 2=0.1827$ \\
$(\Delta / \sigma)_{\text {max }}$ & 0.001 \\
Largest diff. peak and hole & 0.320 and -0.209 e $\AA^{-3}$ \\
Measurement & DIPLabo Kappa \\
Program system & Denzo \\
Structure determination & SHELXS-97 \\
Refinement & full-matrix: SHELXL-97 \\
\hline
\end{tabular}




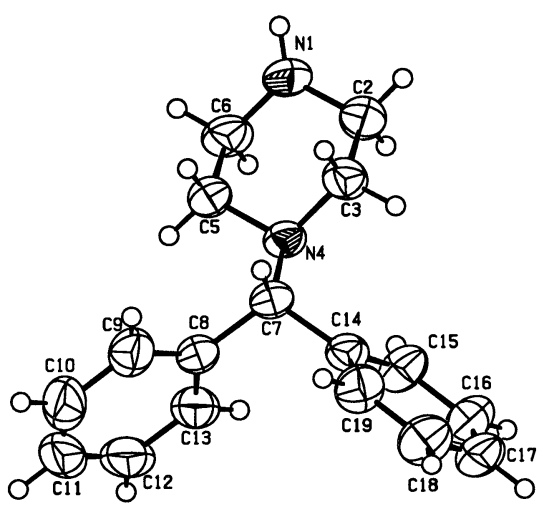

Fig. 2 ORTEP of the molecule at $50 \%$ probability.

Table 2 Selected bond lengths $(\AA)$ and bond angles $\left({ }^{\circ}\right)$

\begin{tabular}{|c|c|c|c|}
\hline Atoms & Length & Atoms & Length \\
\hline N1-C6 & $1.442(2)$ & N4-C5 & $1.460(5)$ \\
\hline $\mathrm{N} 1-\mathrm{C} 2$ & $1.452(2)$ & C8-C7 & $1.524(9)$ \\
\hline N4-C7 & $1.476(7)$ & C7-C14 & $1.522(7)$ \\
\hline N1-C2-C3 & $109.3(1)$ & N4-C7-C8 & $112.5(1)$ \\
\hline N4-C7-C14 & $111.5(1)$ & $\mathrm{C} 15-\mathrm{C} 14-\mathrm{C} 7$ & $122.6(1)$ \\
\hline C8-C9-C10 & $120.2(2)$ & C14-C19-C18 & $121.1(2)$ \\
\hline
\end{tabular}

weighted average ring bond distance of $1.4681(10,108) \AA$ and a weighted average absolute torsion angle of $59.10(8,15)^{\circ}$. The molecules when viewed down the $b$ axis appear to be stacked in pairs. No hydrogen bonding between the molecules is observed.

\section{Acknowledgements}

The authors would like to express their thanks to DST, Government of India, for financial assistance under the project $\mathrm{SP} / \mathrm{I} 2 / \mathrm{FOO} / 93$.

\section{References}

1. Y. Oka, K. Itoh, M. Hirata, US patent, 1980, 4, 582.

2. J-H. Chern, K-S. Shia, T-A. Hsu, C-L. Tai, C-C. Lee, Y-C. Lee, C-S. Chang, S-N. Tseng, and S-R. Shih, Bioorg. Med. Chem. Lett., 2004, 14, 2519.

3. Z. Otwinowski, and W. Minor, "Macromolecular Crystallography”, 1997, 276: part A, ed. C. M. Carter, Jr. and R. M. Sweet, Academic Press, New York, 307 - 326.

4. S. Mackay, C. J. Gilmore, C. Edwards, N. Stewart, and N. Shankland, maXus Computer Program for the Solution and Refinement of Crystal Structures., 1999, Bruker Nonius, The Netherlands, Mac- Science, Japan and The University of Glasgow.

5. G. M. Sheldrick, (SHELXS-97, SHELXL-97), 1997, University of Göttingen, Germany.

6. X. R. Hu, J. M. Gu, and G. L. Lu, Z. Kristallogr., 2003, NCS 218, 497 - 498.

7. D. Cremer and J. A. Pople, J. Am. Chem. Soc., 1995, 97. 